\title{
Neurodevelopmental Correlations between the Korean Developmental Screening Test and Bayley Scale III in Very- Low-Birth-Weight Infants
}

Sol Han, $\mathrm{MD}^{1}$, Oghyang Kim, $\mathrm{MD}^{1}$, Chaeri Yoo, $\mathrm{MD}^{2}$, Ju Sun Heo, $\mathrm{MD}^{3}$, Hyun-Seung Lee, MD, $\mathrm{PhD}^{1}$, and Jihyun Jeon, $\mathrm{MD}, \mathrm{PhD}^{1}$

${ }^{1}$ Department of Pediatrics, CHA Gangnam Medical Center, CHA University, Seoul, Korea

${ }^{2}$ Department of Pediatrics, CHA Bundang Medical Center, CHA University, Seongnam, Korea

${ }^{3}$ Department of Pediatrics, Korea University Anam Hospital, Seoul, Korea

\section{ABSTRACT}

Purpose: We aimed to analyze the correlations between the Bayley Scales of Infant Development (BSID)-III and Korean Developmental Screening Test (K-DST) in very-low-birth-weight (VLBW; birth weight $<1,500 \mathrm{~g}$ ) preterm infants.

Methods: We enrolled 53 VLBW infants (mean gestational age, 28.9 \pm 2.11 weeks; mean birth weight, $1,158.5 \pm 241.1 \mathrm{~g}$ ) and assessed them using the BSID-III and K-DST at a corrected age of 18 to 24 months. We analyzed the correlations between the BSID-III and K-DST subdomains and evaluated whether the estimated developmental levels were consistent with the corrected ages.

Results: In the BSID-III, the composite scores for cognition, motor, and language were $105.9 \pm 13.1$ (median, 105; 66th percentile; $95 \%$ confidence interval [CI], 98 to 113), 100.9 \pm 12.4 (100; 50th percentile; $95 \%$ CI, 92 to 108), and $94.9 \pm 16.8$ (97.5; 34th percentile; $95 \% \mathrm{CI}, 87$ to 102), respectively. The scaled scores for receptive/expressive language and gross/fine motor were $9.9 \pm 2.9$ (10.5)/8.2 \pm 2.7 (8) and 9.6 $\pm 2.4(9) / 10.6$ \pm 2.3 (10), respectively. In the K-DST, the mean scores of cognition (17.8 \pm 4.7 [18.5]), language (16.6 $\pm 7.2[20])$, fine motor (19.4 $\pm 3.4[20])$, gross motor (19.9 \pm 3.8 [21]), sociality (18.6 \pm 4.7 [20]), and self-control (17.3 \pm 5.1 [18]) were within the range of normal developmental status. Among the overlapping subdomains, cognition $(r=0.58, P=$ $0.003)$ and language $(r=0.86, P<0.001)$, but not fine and gross motor status $(r=0.05, P=$ $0.79 ; r=0.16, P=0.44$, respectively), showed significant correlation between the BSIDIII and K-DST.

Conclusion: The language and cognition domains of the K-DST were significantly correlated with the BSID-III in preterm VLBW infants. Clinicians should consider these discrepancies and correlations when evaluating the developmental status of preterm VLBW infants.

Key Words: Infant, very low birth weight; Neurodevelopment; Bayley Scales; Korean Developmental Screening Test

Received: 5 June 2020

Revised: 30 July 2020

Accepted: 6 August 2020

Correspondence to: Jihyun Jeon, MD, $\mathrm{PhD}$

Department of Pediatrics, CHA Gang. nam Medical Center, CHA University, 566 Nonhyeon-ro, Gangnam-gu, Seoul 06135, Korea

Tel: +82-2-3468-3010

Fax: +82-2-3468-2618

E-mail: goddaugh@chamc.co.kr

Copyright(c)

By Korean Society of Neonatology.

All right reserved.

This is an Open-Access article distributed under the terms of the Creative Commons Attribution Non-Commercial License (http:// creativecommons.org/licenses/by-nc/4.0), which permits unrestricted non-commercial use, distribution, and reproduction in any medium, provided the original work is properly cited. 


\section{INTRODUCTION}

The importance of neurodevelopmental screening tests for preterm infants is demonstrated by the improvement in the survival rates of very-low-birth-weight (VLBW) infants (birth weight $<1,500 \mathrm{~g})$. The Bayley Scales of Infant Development (BSID) is the most widely used tool for assessing developmental progress $^{1)}$. The primary scales of the BSID-I and BSID-II are the Mental Developmental Index (MDI) and the Psychomotor Developmental Index (PDI), which evaluate early cognitive/ language development and early motor development, respectively. Both the MDI and PDI have limitations. For example, a low MDI score could reflect a delay in language or cognitive develop ment, or both. The third edition of the Bayley scales, which was published in 2006 for infants and children aged 1 to 42 months, attempted to overcome these limitations by subdividing the composite scores (CS) of the cognitive, language, and motor do mains $^{2,3)}$. Thus, scaled scores (SS) can assess receptive/expressive communication and fine/gross motor development.

The Korean Developmental Screening Test (K-DST) for Infants \& Children is an evaluation tool that is based on a questionnaire completed by primary caretakers. It was developed in 2014 to assess Korean infants' developmental abilities in the domains of gross motor, fine motor, cognition, language, sociality, and self$\operatorname{control}^{4)}$. Although the standard test of premature neurodevelop ment in VLBW infants is the BSID-III at a corrected age of 18 to 24 months, its clinical application is difficult given its time consumption, cost, and infants' general condition during the test. Therefore, the K-DST is generally used as a neurodevelopmental screening test for VLBW infants at the corrected age of 18 to 24 months. However, implementing the K-DST alone may overlook developmental delays in preterm infants.

Here we assessed whether the K-DST could be used as a reliable screening test for cases where clinicians cannot assess VLBW infants using the BSID-III. Therefore, we analyzed the K-DST as a screening test for the timely diagnosis of neurodevelopmental delay in VLBW infants compared to the BSID-III. To our knowledge, this is the first study to assess the correlations between the BSID-III and K-DST.

\section{MATERIALS AND METHODS}

\section{Study population}

From January 2014 to March 2018, we enrolled 53VLBW infants (under 1,500 g) born at CHA Gangnam Medical Center and admitted to the neonatal intensive care unit. All the participants were assessed using the BSID-III performed by examiners and K-DST based on primary caretaker's questionnaire at the cor rected age of 18 to 24 months.

\section{Analysis}

We obtained the gestational age, hospital day, and anthropometry (body weight, height, and head circumference) at birth and at the time of developmental screening for all participants $(\mathrm{n}=53)$ from medical records (Table 1$)$.

The mean BSID-III and K-DST scores were measured for all participants. The SS of the BSID-III were subdivided into five domains: cognitive, receptive language, expressive language, fine motor,and gross motor developmental status. The SS were derived from the total raw subtest scores and ranged from 1 to 19 with a mean of 10 and a standard deviation (SD) of 3 . The CS of the BSID-III consisted of three main domains: cognition, language, and motor developmental status. CS were derived from various totals of subtest SS and were a metric with a mean of 100 and an SD of 155). The percentile rank of the BSID-III indicated where a child ranked relative to children in the standardization sample. Percentile ranks range from 1 to 99 with a mean and median of 505).

The mean value of each CS was analyzed to determine the estimated developmental age. The SS of receptive and expressive

Table 1. Clinical Characteristics of Very-Low-Birth-Weight Infants at Birth and at a Corrected Age of 18 to 24 Months

\begin{tabular}{lc}
\hline Characteristic & Mean \pm SD (median) \\
\hline Gestational age (wk) & $28.9 \pm 2.11(29)$ \\
Birth weight (g) & $1,158.5 \pm 241.1(1,210)$ \\
Birth height (cm) & $37.2 \pm 2.8(37)$ \\
Birth head circumference (cm) & $26.6 \pm 1.9(27.4)$ \\
Hospital days in NICU (d) & $65.6 \pm 20.2(65)$ \\
Body weight (kg)* & $11.2 \pm 1.4(11.4)$ \\
Height $(\mathrm{cm})^{*}$ & $84.1 \pm 3.4(84)$ \\
Head circumference $(\mathrm{cm})^{*}$ & $47.6 \pm 1.9(48)$ \\
\hline
\end{tabular}

*At the time of the developmental screening test. Abbreviations: SD, standard deviation; NICU, neonatal intensive care unit. 
language, as well as those for fine and gross motor status, were compared.

Developmental delay according to the BSID-III was defined as a $\mathrm{CS}$ of $<85(<-1 \mathrm{SD})^{6,7)}$. The definition of developmental delay in the K-DST was a score $<-1$ SD of the peer-level ${ }^{8)}$. The K-DST scores were categorized into the following grades: further evaluation ( $<-2 \mathrm{SD})$, follow-up evaluation $(-2 \mathrm{SD} \leq$ score $<-1 \mathrm{SD})$, peerlevel $(-1 \mathrm{SD} \leq$ score $<1 \mathrm{SD})$, and high level ( $\geq 1 \mathrm{SD})$. Therefore, we analyzed the BSID-III and K-DST by each grade.

The domains of cognition, language, fine motor, and gross motor overlapped in both the BSID-III and K-DST. These domains were analyzed to determine the correlation between the two tests.

\section{Statistical analysis}

The results are presented as mean \pm SD (median) for variable distribution. Student's $t$-test was used to determine any significant differences between receptive and expressive language and fine and gross motor status. The chi-square test was used for between-scale analysis. Spearman's rank correlation coefficient was used to evaluate the relationship between the BSID-III and K-DST. All statistical analyses were performed using STATA version 13 (Stata Corp., College Station, TX, USA) and $P<0.05$ was considered to indicate statistical significance.

Table 2. Mean Scores for the BSID-III and K-DST

\begin{tabular}{lc}
\hline Variable & Mean \pm SD (median) \\
\hline BSID-III & $105.9 \pm 13.1(105)$ \\
Cognition (CS) & $94.9 \pm 16.8(97.5)$ \\
Language (CS) & $9.9 \pm 2.9(10.5)$ \\
Receptive (SS) & $8.2 \pm 2.7(8)$ \\
Expressive (SS) & $100.9 \pm 12.4(100)$ \\
Motor (CS) & $10.6 \pm 2.3(10)$ \\
Fine (SS) & $9.6 \pm 2.4(9)$ \\
Gross (SS) & \\
K-DST & $17.8 \pm 4.7(18.5)$ \\
Cognition & $16.6 \pm 7.2(20)$ \\
Language & $19.4 \pm 3.4(20)$ \\
Fine motor & $19.9 \pm 3.8(21)$ \\
Gross motor & $18.6 \pm 4.7(20)$ \\
Sociality & $17.3 \pm 5.1(18)$ \\
Self-control &
\end{tabular}

Abbreviations: BSID, Bayley Scales of Infant Development; K-DST, Korean Developmental Screening Test; SD, standard deviation; CS, composite score; SS, scaled score.

\section{RESULTS}

We enrolled 53 infants with a mean gestational age of $28.9 \pm 2.1$ weeks (29) and average birth weight of 1,158.5 $\pm 241.1 \mathrm{~g}(1,210)$. At the time of their developmental screening, the corrected age (range 18 to 24 months) and mean body weight (11.2 $\pm 1.4 \mathrm{~kg}$ [11.4]) were within the normal percentile (Table 1).

Table 2 shows the results of the BSID-III and K-DST. In the BSID-III, the CS of cognition was 105.9 \pm 13.1 (105) while that of language, which was derived by combining the SS, was $94.9 \pm 16.8$ (97.5). Receptive language (9.9 \pm 2.9 [10.5]) had a significantly higher mean SS than expressive language (8.2 \pm 2.7 [8]; $P=0.001$ ). Regarding motor development, the SS for gross motor $(9.6 \pm 2.4$ [9]) was significantly lower than the fine motor SS (10.6 \pm 2.3 [10]; $P=0.013)$. The CS for motor status, which was the sum of SS, was $100.9 \pm 12.4$ (100). In the K-DST, the mean scores of cognition (17.8 \pm 4.7 [18.5]), language (16.6 \pm 7.2 [20]), fine motor $(19.4 \pm 3.4$ [20]), gross motor $(19.9 \pm 3.8[21])$, sociality (18.6 $\pm 4.7[20])$, and self-control (17.3 \pm 5.1 [18]) were within the limits of normal developmental status. There were five infants in rehabilitation; although their gross motor assessment by the K-DST was "followup evaluation (<-1 SD)," their motor status according to the BSID-III was not delayed.

Tables 3-5 show the correlation test results between neurodevelopment delay according to the BSID-III and delay accord ing to the K-DST for each grade in VLBW infants. There was no significant correlation between the cognition domains of the BSID-III and K-DST ( $P=0.540$ ) (Table 3). However, there was a significant correlation between the language domains of the BSID-III and K-DST ( $P=0.001)$ (Table 4). In the K-DST, two further evaluations were confirmed as delays, while in the BSID-III, 11 out of 17 follow-up evaluations were confirmed as delays. However, four out of 16 peer levels were delayed in the BSID-III. As

Table 3. Cross-Tabulation Analysis of Cognition between the Bayley Scales of Infant Development-III and K-DST in VeryLow-Birth-Weight Infants

\begin{tabular}{|c|c|c|c|c|}
\hline \multirow{2}{*}{ K-DST } & \multirow{2}{*}{$\begin{array}{c}\text { Developmental } \\
\text { level }\end{array}$} & \multicolumn{2}{|c|}{ Cognition, n (\%) } & \multirow{2}{*}{$P$-value } \\
\hline & & $<85(-1 \mathrm{SD})$ & $\geq 85$ & \\
\hline \multirow[t]{4}{*}{ Cognition } & Further evaluation & $0(0)$ & $2(3.9)$ & 0.540 \\
\hline & Follow-up evaluation & $1(100)$ & $16(30.8)$ & \\
\hline & Peer level & $0(0)$ & $15(28.9)$ & \\
\hline & High level & $0(0)$ & $19(36.4)$ & \\
\hline
\end{tabular}

Abbreviations: K-DST, Korean Developmental Screening Test; SD, standard deviation. 
for motor status, there was a significant correlation between the motor status of the BSID-III and the fine motor domain of the K-DST $(P=0.006)$ (Table 5).

The domains of cognition, language, and fine/gross motor overlapped in the BSID-III and K-DST. The rho score $(r)$ for cog nition was $0.58(P=0.003)$ and the $r$-value of language was 0.87 $(P<0.001)$, which indicated a significant correlation between the BSID-III and K-DST (Table 6). However, there was no significant between-scale correlation in fine and gross motor status.

Table 4. Cross-Tabulation Analysis of Language between the Bayley Scales of Infant Development-III and K-DST in VeryLow-Birth-Weight Infants

\begin{tabular}{|c|c|c|c|c|}
\hline \multirow{2}{*}{ K-DST } & \multirow{2}{*}{$\begin{array}{c}\text { Developmental } \\
\text { level }\end{array}$} & \multicolumn{2}{|c|}{ Language, $n(\%)$} & \multirow{2}{*}{$P$-value } \\
\hline & & $<85(-1 \mathrm{SD})$ & $\geq 85$ & \\
\hline \multirow[t]{4}{*}{ Language } & Further evaluation & $2(11.8)$ & $2(5.6)$ & 0.001 \\
\hline & Follow-up evaluation & $11(64.7)$ & $6(16.7)$ & \\
\hline & Peer level & $4(23.5)$ & $12(33.3)$ & \\
\hline & High level & $0(0)$ & $16(44.4)$ & \\
\hline
\end{tabular}

Abbreviations: K-DST, Korean Developmental Screening Test; SD, standard deviation.

Table 5. Cross-Tabulation Analysis of Motor between the Bayley Scales of Infant Development-III and K-DST in Very-LowBirth-Weight Infants

\begin{tabular}{lllll}
\hline \multirow{2}{*}{ K-DST } & \multicolumn{1}{c}{$\begin{array}{c}\text { Developmental } \\
\text { level }\end{array}$} & \multicolumn{2}{c}{ Language, $\mathrm{n}(\%)$} & \\
\cline { 3 - 4 } & & \multicolumn{2}{c}{ P-value } \\
Gross motor $(-1 \mathrm{SD})$ & $\geq 85$ & \\
\cline { 2 - 4 } & Further evaluation & $0(0)$ & $0(0)$ & 0.258 \\
& Follow-up evaluation & $2(100)$ & $10(19.6)$ & \\
& Peer level & $0(0)$ & $21(41.2)$ & \\
& High level & $0(0)$ & $20(39.2)$ & \\
& Further evaluation & $0(0)$ & $0(0)$ & 0.006 \\
& Follow-up evaluation & $2(100)$ & $7(13.7)$ & \\
& Peer level & $0(0)$ & $21(41.2)$ & \\
& High level & $0(0)$ & $23(45.1)$ &
\end{tabular}

Abbreviations: K-DST, Korean Developmental Screening Test; SD, standard deviation.

Table 6. Analysis of Mutual Relationships between the Bayley Scales of Infant Development-III and the Korean Developmental Screening Test

\begin{tabular}{lcc}
\hline Domains & $r^{*}$ & $P$-value \\
\hline Cognition & 0.58 & 0.003 \\
Language & 0.87 & $<0.001$ \\
Fine motor & 0.05 & 0.79 \\
Gross motor & 0.16 & 0.44 \\
\hline
\end{tabular}

*Spearman's rank correlation analysis.

\section{DISCUSSION}

Developmental screening tests are very important for early detection and diagnosis of developmental delays ${ }^{9,10)}$. Preterm and low birth weight infants are at a higher risk of neurodevelop mental problems. Furthermore, some developmental delays can be resolved with early interventions and subsequent treatment $^{11-13)}$.

The K-DST was developed in September 2014 and standardized for Korean infants and children ${ }^{14)}$. It is an appropriate screening tool with excellent reliability and validity as well as clinical signifi cance $^{4,14,15)}$. The BSID-III can evaluate cognition, language, and motor domains as separate CS, as well as assess developmental level, by subdividing the sections into "receptive language," "expressive language," and "fine and gross motor" using $\mathrm{SS}^{3)}$. Therefore, it avoids problems associated with the lack of standardized scores for cognitive vs. language skills and gross vs. fine motor skills ${ }^{16)}$. Both the K-DST and Bayley Scales are used to assess longterm neurodevelopmental outcomes for VLBW infants ${ }^{17)}$.

Language delay could be an early sign of neurodevelopmental disorders, including attention deficit hyperactivity disorder, au tism spectrum disorder, or specific language impairment ${ }^{18,19)}$. Previous studies have shown that VLBW infants perform worse in overall expressive and receptive language compared with in fants in a control group and may be at risk of experiencing early delays in expressive language skills ${ }^{20,21)}$. Adams-Chapman et $\mathrm{al}^{22)}$ found that among 467 VLBW infants, 55\% and 23\% had difficulties in receptive and expressive language development, respectively. Consistent with previous findings, we found that the mean of language in preterm VLBW infants (CS 94.9, 37th percentile rank) was below the average (CS 100, 50th percentile rank). Moreover, preterm VLBW infants had more difficulties in expressive language (SS 8.2, 25th percentile rank), which was significantly lower than the scores for receptive language (SS 9.9, 50th percentile rank). Thus, although the language score was within the normal range for VLBW infants in developmental screening, clinicians should consider language therapy in case of delayed expressive language development.

Regarding motor development, delays are more common in VLBW infants and significant motor impairment persists through out childhood ${ }^{23,24)}$. However, the VLBW infants in this study had normal motor developmental status according to both the BSID-III and K-DST. There were five infants in rehabilitation and although their gross motor evaluation according to the K-DST 
was "follow-up evaluation (<-1 SD)," their motor status according to the BSID-III was not delayed. Other than rehabilitation, the normal motor score of the BSID-III could be attributed to the treatment of infants with severely delayed development at other higher hospitals with improvement through rehabilitation.

According to the correlation analysis of the individual domains of the K-DST and BSID-II in VLBW infants by Kim et al. ${ }^{25)}$, four domains (fine motor, cognition, language, and sociality) were significantly associated with BSID-II MDI, but not BSID-II PDI, scores. This is the first study regarding the BSID-III and K-DST. However, Kim's results are consistent with ours. As shown in Table 4, the language score of the BSID-III was significantly associated with the K-DST. However, $23.5 \%$ of the K-DST peer levels had delays on the BSID-III in language. Regarding VLBW preterm infants, the peer level of the K-DST can be referred to for the developmental level; however, a lack of a delay in language cannot be determined. Therefore, there is a need to evaluate the language developmental state through regular follow-up.

With respect to the correlation between the BSID-III and K-DST for language, cognitive, and motor development, the Spearman's rho $(r)$ for language development was $0.87(P<0.001)$,which indicated a high correlation. The $r$-value for cognitive development was $0.58(P=0.025)$ (Table 6$)$, also indicating a significant correlation. Contrastingly, there was no correlation in motor development. With respect to gross motor dysfunction, previous studies have reported a moderate, positive correlation of the K-DST with the BSID-II ${ }^{26)}$. There have not been any studies comparing motor development on the K-DST and BSID-III. This study was based on preterm infants with a significantly different trajectory in their gross motor development in the first 18 months of life compared with term infants ${ }^{27)}$. Thus, it is difficult to generalize the results regarding motor development relevance between the K-DST and BSID-III. There is a need for future studies regarding motor development relevance on various criteria.

Our findings are inconsistent with those by Kim et al. ${ }^{25)}$, who analyzed the relationship between the K-DST and BSID-II. In the study by Kim et al. ${ }^{27)}$, the $r$-values for cognition, language, and sociality were $0.498(P<0.0001), 0.526(P<0.0001)$, and 0.384 $(P<0.0001)$, respectively. However, they reported between-scale correlations in cognition and language, which were consistent with our findings. Further, Kwun et al. ${ }^{28)}$ assessed the relationship between standard and screening tests; specifically, the correlation of the BSID-II and the Ages and Stages Questionnaire (ASQ) in Korean for preterm infants at a corrected age of 18 to
24 months. Compared with our study, the study by Kwun et al. ${ }^{28)}$ used different participants (<37 weeks) and type of questionnaire (ASQ). However, communication and the MDI showed a moderate correlation $(r=0.385, P<0.001)$ in Kwen's study. Compared with the two aforementioned studies, our study had the highest $r$-value. Specifically, the $r$-value of 0.87 for language development suggests a high concurrence between the BSID-III and K-DST. However, the lower-than-expected $r$-value of cognition develop ment could be attributed to the small number of participants.

Developmental screening tests based on parental questionnaires are known to have strong correlations with the BSID-III in the areas of language and cognitive development ${ }^{29)}$. Similarly, we observed significant mutual relationships in the evaluation of cognition and language development between the K-DST and BSID-III. Parents or primary caretakers provide reliable in formation regarding the range of a child's abilities ${ }^{30)}$. However, the correlation of parental versus inspector reports on the evaluation for motor development remains unclear and further studies are needed.

There are limitations that should be acknowledged. The small number of included participants $(n=53)$ limits the accuracy of the analysis. Three separate examiners performed assessments using the BSID-III, which impedes standardization and could have led to inter-observer discrepancies. Further, we compared the scores among VLBW infants. To examine the developmental status of VLBW infants, further analysis comparing them with full-term infants of adequate birth weight is necessary.

In summary, among infants with a birth weight $<1,500 \mathrm{~g}$, the delay of expressive language was more significant than that of receptive language. Regarding language and cognitive develop ment in VLBW infants, the K-DST was strongly correlated with the BSID-III. However, there was no between-scale association in motor development.

In conclusion, when clinicians cannot assess VLBW infants using the BSID-III, they could assess neurodevelopment of the cognitive and language domains using the K-DST. If the cognition and language grades are follow-up or further evaluation according to the K-DST, VLBW infants should be examined using the standard BSID test. Clinicians should consider the discrepancies and concurrence of the two developmental tests when evaluating the developmental status of preterm VLBW infants. 


\section{ARTICLE INFORMATION}

\section{Ethics statement}

The present study protocol was reviewed and approved by the Institutional Review Board of Gangnam CHA Medical Center, CHA University (approval No. GCI-20-10). Written informed consent was obtained from the legal guardians of all the enrolled participants.

\section{Conflicts of interest}

No potential conflict of interest relevant to this article was reported.

\section{Author contributions}

Conception or design: S.H., O.K., C.Y., J.S.H., H.S.L., J.J.

Acquisition, analysis, or interpretation of data: J.S.H., J.J.

Drafting the work or revising: S.H., H.S.L., J.J.

Final approval of the manuscript: O.K., C.Y., J.S.H., H.S.L., J.J.

\section{ORCID}

Sol Han https://orcid.org/0000-0003-3184-2414

Jihyun Jeon https://orcid.org/0000-0002-4512-2728

\section{Acknowledgments}

None

\section{REFERENCES}

1. Luttikhuizen dos Santos ES, de Kieviet JF, Konigs M, van Elburg $\mathrm{RM}$, Oosterlaan J. Predictive value of the Bayley scales of infant development on development of very preterm/very low birth weight children: a meta-analysis. Early Hum Dev 2013;89:48796.

2. Anderson PJ, de Luca CR, Hutchinson E, Roberts G, Doyle LW; Victorian Infant Collaborative Group. Underestimation of de velopmental delay by the new Bayley-III Scale. Arch Pediatr Adolesc Med 2010;164:352-6.

3. Jeong SU, Kim GC, Jeong HJ, Kim DK, Hong YR, Kim HD, et al. The validity of the Bayley-III and DDST-II in preterm infants with neurodevelopmental impairment: a pilot study. Ann Rehabil Med 2017;41:851-7.

4. Moon JS, Lee SY, Eun BL, Kim SW, Kim YK, Shin SM, et al. Oneyear evaluation of the national health screening program for infants and children in Korea. Korean J Pediatr 2010;53:307-13.

5. Bayley N. Bayley scales of infant and toddler developmental. 3rd ed. San Antonio: Pearson, 2006:4-5.

6. Johnson S, Moore T, Marlow N. Using the Bayley-III to assess neurodevelopmental delay: which cut-off should be used? Pediatr Res 2014;75:670-4.

7. Spittle AJ, Spencer-Smith MM, Eeles AL, Lee KJ, Lorefice LE, Anderson PJ, et al. Does the Bayley-III Motor Scale at 2 years predict motor outcome at 4 years in very preterm children? Dev Med Child Neurol 2013;55:448-52.

8. Eun BL, Chung HJ. Korean development screening test for infants and children. Cheongju: Korea Centers for Disease Control and Prevention, 2014.

9. Edwards SL, Sarwark JF. Infant and child motor development. Clin Orthop Relat Res 2005;434:33-9.

10. Eun BL, Chung HJ, Cho S, Kim JK, Shin SM, Lee JH, et al. The appropriateness of the items of Korean Ages and Stages Ques tionnaires (K-ASQ) developmental screening test in Korean infants and children. J Korean Child Neurol Soc 2014;22: 29-41.

11. Colvin M, McGuire W, Fowlie PW. Neurodevelopmental out comes after preterm birth. BMJ 2004;329:1390-3.

12. Im SH, Han EY, Song J. Clinical application of neurodevelop mental assessment for infants and toddlers. J Korean Acad Child Adolesc Psychiatry 2012;23:175-80.

13. Eun BL, Moon JS, Eun SH, Lee HK, Shin SM, Sung IK, et al. The current child and adolescent health screening system: an assessment and proposal for an early and periodic check-up program. Korean J Pediatr 2010;53:300-6.

14. Yim CH, Kim GH, Eun BL. Usefulness of the Korean Develop mental Screening Test for infants and children for the evaluation of developmental delay in Korean infants and children: a singlecenter study. Korean J Pediatr 2017;60:312-9.

15. Suh CR, Sohn SY, Kim GH, Jung SK, Eun BL. Single-center ex perience of the Korean-Developmental Screening Test for infants and children. Korean J Pediatr 2016;59:483-9.

16. Johnson S, Marlow N. Developmental screen or developmental testing? Early Hum Dev 2006;82:173-83.

17. Youn Y, Lee SM, Hwang JH, Cho SJ, Kim EK, Kim EA, et al. National registry data from Korean neonatal network: two-year outcomes of Korean very low birth weight infants born in 20132014. J Korean Med Sci 2018;33:e309.

18. Bruce B, Thernlund G, Nettelbladt U. ADHD and language impairment: a study of the parent questionnaire FTF (Five to Fifteen). Eur Child Adolesc Psychiatry 2006;15:52-60.

19. Geurts HM, Embrechts M. Language profiles in ASD, SLI, and ADHD. J Autism Dev Disord 2008;38:1931-43.

20. Barre N, Morgan A, Doyle LW, Anderson PJ. Language abilities in children who were very preterm and/or very low birth weight: a meta-analysis. J Pediatr 2011;158:766-74.

21. Kunnari S, Yliherva A, Paavola L, Peltoniemi OM. Expressive language skills in Finnish two-year-old extremely- and verylow-birth-weight preterm children. Folia Phoniatr Logop 2012; 
64:5-11.

22. Adams-Chapman I, Bann C, Carter SL, Stoll BJ; NICHD Neonatal Research Network. Language outcomes among ELBW infants in early childhood. Early Hum Dev 2015;91:373-9.

23. Fernandes LV, Goulart AL, Santos AM, Barros MC, Guerra CC, Kopelman BI. Neurodevelopmental assessment of very low birth weight preterm infants at corrected age of 18-24 months by Bayley III scales. J Pediatr (Rio J) 2012;88:471-8.

24. De Kieviet JF, Piek JP, Aarnoudse-Moens CS, Oosterlaan J. Motor development in very preterm and very low-birth-weight children from birth to adolescence: a meta-analysis. JAMA 2009;302:2235-42.

25. Kim CY, Jung E, Lee BS, Kim KS, Kim EA. Validity of the Korean Developmental Screening Test for very-low-birth-weight in fants. Korean J Pediatr 2019;62:187-92.

26. Jang CH, Kim SW, Jeon HR, Jung DW, Cho HE, Kim J, et al. Clinical usefulness of the Korean Developmental Screening Test (K-DST) for developmental delays. Ann Rehabil Med 2019;
43:490-6.

27. Van Haastert IC, de Vries LS, Helders PJ, Jongmans MJ. Early gross motor development of preterm infants according to the Alberta Infant Motor Scale. J Pediatr 2006;149:617-22.

28. Kwun Y, Park HW, Kim MJ, Lee BS, Kim EA. Validity of the ages and stages questionnaires in Korean compared to Bayley Scales of infant development-II for screening preterm infants at corrected age of 18-24 months for neurodevelopmental delay. J Korean Med Sci 2015;30:450-5.

29. Blaggan S, Guy A, Boyle EM, Spata E, Manktelow BN, Wolke $\mathrm{D}$, et al. A parent questionnaire for developmental screening in infants born late and moderately preterm. Pediatrics 2014; 134:e55-62.

30. Perra O, McGowan JE, Grunau RE, Doran JB, Craig S, Johnston $\mathrm{L}$, et al. Parent ratings of child cognition and language compared with Bayley-III in preterm 3-year-olds. Early Hum Dev 2015;91:211-6. 